University of South Carolina

Scholar Commons

$7-2010$

\title{
Does Context Matter in Determining Psychological Abuse? Effects of Pattern, Harm, Relationship, and Norms
}

\author{
Dana D. DeHart \\ University of South Carolina - Columbia, dana.dehart@sc.edu \\ Diane R. Follingstad \\ University of Kentucky \\ Alice M. Fields \\ University of South Carolina - Columbia
}

Follow this and additional works at: https://scholarcommons.sc.edu/sowk_facpub

Part of the Social Work Commons

\author{
Publication Info \\ Postprint version. Published in Journal of Family Violence, Volume 25, Issue 5, 2010, pages 461-474. \\ DeHart, D. D., Follingstad, D. R., \& Fields, A. M. (2010). Does context matter in determining psychological \\ abuse? Effects of pattern, harm, relationship, and norms. Journal of Family Violence, 25(5), 461-470. DOI: \\ 10.1007/s10896-010-9307-7 \\ (c) Journal of Family Violence, 2010, Springer Verlag \\ The original publication is available at www.springerlink.com/content/q50q4424m3174103/
}

This Article is brought to you by the Social Work, College of at Scholar Commons. It has been accepted for inclusion in Faculty and Staff Publications by an authorized administrator of Scholar Commons. For more information, please contact digres@mailbox.sc.edu. 
POST-PRINT VERSION: DeHart, D. D., Follingstad, D. R., \& Fields, A. M. (2010). Does context matter in determining psychological abuse? Effects of pattern, harm, relationship, and norms. Journal of Family Violence, 25(5), 461-474, DOI: 10.1007/s10896-010-9307-7.

\title{
Does Context Matter in Determining Psychological Abuse? \\ Effects of Pattern, Harm, Relationship, and Norms
}

\author{
Dana D. DeHart ${ }^{1}$
}

Diane R. Follingstad ${ }^{2}$

Alice M. Fields ${ }^{3}$

1 (Corresponding author) Center for Child \& Family Studies, College of Social Work, University of South Carolina, Columbia, SC 29208; dana.dehart@ @sc.edu; 803-777-7867.

2 Center for Research on Violence Against Women \& Department of Psychiatry, College of Medicine, University of Kentucky, Lexington, KY.

3 Department of Psychology, University of South Carolina, Columbia, SC. 


\begin{abstract}
This study explored contextual influences in determining whether psychologically aggressive actions constitute abuse. One hundred and thirty-one undergraduates completed measures of key experiences, attitudes, and traits, and rated abusiveness of behaviors in a series of vignettes. Vignettes varied contexts in which behaviors occurred, including whether the behavior was a pattern, whether there was harm to the recipient, characteristics of the initiator-recipient relationship, and whether behavior was normative. Results showed no effects for participants' gender, past experiences with psychological aggression, and traits or attitudes. Findings indicated that behaviors were rated as more abusive when harm to the recipient was evident. Findings regarding patterns of behavior, relationship, and normative contexts were less consistent. Implications for measurement of psychological abuse are discussed.
\end{abstract}

Keywords: emotional abuse; psychological aggression; verbal abuse; violence. 
Strong claims have been made as to the destructive impact of psychological aggression in intimate relationships (Aguilar \& Nightingale, 1994; Straight, Harper, \& Arias, 2003; Vivian \& Langhinrichsen-Rohling, 1994). However, a number of researchers have cautioned the adoption of assumptions that seem to be promoted as facts in this emerging field of inquiry. O’Leary (2001) reported that "adequate definitions of psychological abuse in relationships do not exist for legal and formal diagnostic purposes" (p. 22); Maiuro (2001) stated that "we are far from developing reliable 'norms' regarding these behaviors" (p.xvi); and Follingstad (2007) claimed that the field was now in the "awkward and essentially untenable position" of trying to "make sense of a prolific amount of data regarding a phenomenon that has been inadequately conceptualized" (p. 441).

Psychological aggression has been measured almost exclusively through self-reported endorsement of briefly stated items on a checklist. In addition to the myriad problems inherent in collecting self-report data on sensitive topics, this approach seems to turn a blind eye to the interpersonal nature of psychological interchanges in intimate relationships as well as ignore nuances of and contextual meanings for these types of behaviors. Researchers have already determined that these brief checklist items are not viewed similarly by all clinicians (Follingstad \& DeHart, 2000), or by psychologists versus lay persons (Follingstad et al., 2004b). In addition, psychologists do not rate these as constituting similar levels of abuse when the behaviors are enacted by a husband versus a wife (Follingstad et al., 2004a). Follingstad (2008) found a discrepancy between participant ratings of how often psychologically aggressive behaviors occurred and how often participants felt the actions were actually abusive, such that behaviors occurred more often than they were designated "abusive." Loring (1994) proposed a quantitative criterion for labeling behaviors as abuse, suggesting that a pattern of aversive behaviors (i.e., higher frequency or longer duration) be present to meet a threshold indicative of abuse. Such a criterion could certainly be important for evaluating behaviors deemed to be "milder" psychological aggression, although a pattern in and of itself may be 
inadequate for establishing that abuse occurred. Follingstad and DeHart (2000) found that psychologists overwhelmingly reported that if they knew psychologically aggressive behaviors were of high frequency or of longer duration in an intimate relationship, they would be strongly influenced to consider the behavior as "abusive," whereas they would be much less certain if they knew the behavior had only occurred once.

A more important criterion than frequency or duration might be knowledge of the sequence of actions between partners. This sequence could inform whether a psychologically aggressive action was a one-time event, an ongoing pattern of unilateral aggression, the initiator's response to some apparent provocation by the recipient, or an escalating series of "tit-for-tat" actions between the initiator and recipient. If a preceding behavior by one's partner was psychologically aggressive, a reactive psychologically aggressive behavior might even be considered "psychological self-defense." Kowalski (2001) reported that responses to aversive interpersonal behaviors range from revenge to forgiveness, to resignation, to distancing, to confrontation, and that "the more aversive a behavior is perceived to be, the more likely a target is to respond aversively" (p. 15). Thus, it would seem highly problematic to assess a particular psychologically aggressive action in a vacuum without some knowledge of how the incident may be associated with similar past incidents between the initiator and recipient, or even when in a chain of events the aversive behavior occurred.

Follingstad (2007) more thoroughly considered the role of context as influencing whether a psychological action would be considered neutral, aggressive, or abusive. The impact or outcome of psychologically aggressive actions was cited as one potential context for consideration. A number of researchers have even suggested that a negative outcome be required as part of the definition of “psychological abuse” (e.g., Hoffman, 1984; Murphy \& Hoover, 1999), but "no clear path models have been documented for which forms or levels of psychologically aggressive behaviors produce specific outcomes, and partialing out prior symptomatology, other aspects of the relationship, 
and/or concurrent historical events which could cause the reported effects is difficult" (Follingstad, 2007, p. 450). Complicating assessment of the potential harm of psychological aggression is the interaction of one partner's behavior with the other partner's threshold or sensitivity for harm, attitudes and beliefs about intimate relationships, or even personality traits--such as rigidity--which can all influence interpretation of the partner's intentions. Even so, it is likely that reasonably linked negative effects would lead people to judge the psychologically aggressive actions as more abusive in nature.

Relationship dynamics may actually ameliorate the perception of abuse for some behaviors. For example, lay persons were less likely than psychologists to view jealous actions or monitoring behaviors as abusive (Follingstad et al., 2004b), which is in line with findings from dating violence studies suggesting that couples in longer relationships believe they have more of a right to control their partner's actions (e.g., Laner \& Thompson, 1982). O’Leary (2001) reminds us that psychological aggression is commonly found among happily married couples, which seems to imply that some of the same behaviors may have differential effects based on overall relationship satisfaction. Thus, contextual variables of relationship length, level of commitment between partners, the decision to be in an exclusive relationship, and general climate of the relationship may all influence interpretation or perceived aversiveness of psychologically aggressive actions.

Because relationship experiences occur in the context of broader social systems and are sometimes framed by normative influences (Follingstad, 2007), the resulting schemas may also be salient for individuals' interpretations of the meaning and nature of interpersonal intimate behaviors (McGoldrick et al., 1996). Specifically, a psychological action may be labeled as abuse because it occurred in the presence of others, because others outside the relationship judged it to be so, or because normative information suggested it was or was not abusive.

The purpose of the current study is to explore whether laypersons consider contextual 
influences in determining whether psychologically aggressive actions constitute abuse. This has implications for validity of current measurement of psychological abuse given that research respondents typically report on occurrence of behaviors without providing any information regarding the broader context in which events took place. Participants were asked to rate abusiveness of behaviors portrayed in vignettes of dating couples. These vignettes included variation in contexts in which the behavior occurred, such as variation in the pattern or sequence of behavior (e.g., one-time event versus ongoing behavior, behavior as extending from provocation or argument), whether harm to the recipient was evident (e.g., recipient felt hurt, recipient is sensitive to remarks), relationship dynamics (e.g., casual versus exclusive relationship, happy versus conflictual relationship), and social exposure or norms (e.g., behavior occurs in public versus private, behavior is supported by peers). Additional measures of past experiences of psychological aggression, participant response bias, personality traits, and attitudes were included to determine whether these had any bearing on abusiveness ratings.

\section{Method}

\section{Participants}

Participants were recruited through a psychology department pool of undergraduates who participate in research for course credit. To obtain a dating sample relevant to the purposes of the study, only persons identifying as heterosexual, who have never been married, and who have been in a dating relationship for at least three months were eligible for participation. Before participants completed computer-administered measures on SurveyMonkey.com, all participants were required to read informed consent information and were given opportunity to opt out of the experiment. If they wished to proceed, they indicated that they have read and understood the informed consent and had the option of printing off a copy of the informed consent form. 
Thirty of the 161 students recruited through the participant pool did not meet eligibility criteria and were screened out of the data set based on responses to demographic items. This left 131 cases for analyses, the vast majority of whom (95\%) fell within the traditional college student age range of 18 to 22 years old. The sample was predominantly female $(72 \%)$ and included persons identifying as Caucasian (73\%), African American (16\%), Asian (4\%), and Hispanic (2\%). No participants identified as Native American or Alaskan Native, less than two percent identified as "other," and three percent did not indicate ethnic/racial identification. Participants indicated a wide range of college majors including psychology, criminal justice, liberal arts, sciences, health studies, business, journalism, and other majors.

\section{Measures}

\section{$\underline{\text { Context Vignettes }}$}

To explore influence of context on perceptions of psychological aggression, 17 pairs of vignettes described dating couples involved in some form of psychological aggression but a contextual aspect in which the aggression occurred was varied. Based on previous work (Follingstad et al., 2005), we included items representing numerous types of psychologically aversive behaviors (e.g., verbal abuse, jealousy, deceit) and varying in severity from mild (e.g., pointing out partner's small personal flaws) to moderate (e.g., insisting that all relationship problems are partner's fault) to severe (e.g., threatening the partner with physical violence). These items provided a range of psychologically aggressive behaviors to serve as a backdrop for our exploration of contextual effects.

Four types of contexts were explored: pattern or sequence of behavior (e.g., isolated event versus continuation of pattern), harm to the recipient as evident (e.g., recipient as bothered), relationship dynamics (e.g., casual versus exclusive relationship), and behavior evaluated as normative (e.g., peer support or rationale for behavior). For this initial exploration of context effects, we attempted to examine various contexts across the range of the 17 psychologically 
aggressive behaviors versus systematically varying each context across each action, in that the number of items required for the latter would have been burdensome both for research participants and for analytic purposes. Thus, for each of the 17 behaviors, two conditions were created representing differences on a contextual variable, one of which was expected to lead to lesser ratings of abusiveness of the psychologically aggressive behavior (e.g., no harm evident) and one which was expected to lead to greater ratings of abusiveness of the same psychologically aggressive behavior (e.g., harm evident). Appendix I displays the 17 items as manipulated under each of the two contextual conditions.

Finally, to allow assessment of differential effects of initiator's gender across contexts, we included gender as another factor. Two versions of each vignette in Appendix I were written: one in which a male initiated the psychologically aggressive behavior toward a female recipient, and one in which a female initiated the psychologically aggressive behavior toward a male recipient.

In this 2 x 2 (context $x$ gender of initiator) design, half of the participants read vignettes portraying half of the contexts for the psychologically aggressive behaviors, and the other half of participants read vignettes portraying the other half of contexts for the psychologically aggressive behaviors. The halves were varied such that some of the vignettes expected to produce lower ratings and some of those expected to produce higher ratings were included in each half. Within these halves, vignettes portrayed males as initiating the psychologically aggressive behavior half of the time, and portrayed females as initiating the psychologically aggressive behavior half of the time.

Instructions to participants indicated that "psychological abuse" was being defined as the severe and extreme forms of psychological aggression which went beyond "bad relationship behavior" and which inflicted or had the potential to inflict harm (see Appendix II). Rating options for each vignette ranged from $1=$ "not psychologically abusive at all" to $10=$ "extremely psychologically abusive." Participants were instructed to consider the full range of rating options in 
rating vignettes.

Participants' Initiation and Receipt of Psychological Aggression

After rating vignettes, participants completed the Follingstad Psychological Aggression Scale (FPAS; Follingstad, Coyne, \& Gambone, 2005) to assess their own lifetime experience initiating and/or being the recipient of psychologically aggressive behaviors in a dating relationship. The FPAS is a 51-item measure of psychologically aggressive actions including multiple types of behavior (e.g., threats, control over personal behavior, blaming) with mild, moderate, and severe representations of each type. In previous research on ratings of abusiveness of each behavior, the FPAS has demonstrated Cronbach alphas exceeding 0.92 for each severity subscale and for the overall scale, as well as demonstrating high discriminant validity from trait measures. For the current purposes, participants indicated on the FPAS which behaviors they had ever been the recipient of and which behaviors they had ever initiated in dating relationships of their own.

Measures of Response Bias, Attitudes, and Traits

Participants completed eight additional measures to establish that ratings on the context vignettes were not simply a function of potentially related response bias, attitudes, or personality traits. All of the following measures demonstrate established reliability and validity and were measured on their original scales (Likert-type scales ranging from five-point to seven-point scales).

Balanced Inventory of Desirable Responding. To determine whether ratings of behaviors as psychological abuse were influenced by social-desirability response bias, the Balanced Inventory of Desirable Responding (Paulhus, 1988) was administered. This 40-item measure has subscales to measure 1) self-deception, which implies that the person is basically honest but unaware of their desire to view themselves in overly positive ways, and 2) impression-management, which implies that the person endorses known unlikely behaviors because he/she wishes to be viewed as a virtuous person. 
Interpersonal Sensitivity, Paranoia, and Hostility. Perceptions of behaviors as abusive could also be influenced by a general negative perception toward others, with the person expecting that partners in intimate relationships would harm them. To assess whether interpersonal styles, such as sensitivity, suspiciousness, and hostility, might influence the interpretation of psychological actions as more "abusive," we administered these subscales of the Symptom Checklist 90-Revised (Evenson et al., 1980). They constitute 21 items regarding the extent to which symptoms have bothered the individual in the past six months.

Sex Roles. Perceptions of abusiveness might also stem from one's beliefs as to how the sexes should relate to each other. A 20-item scale measuring attitudes toward feminism (Smith, Ferree, \& Miller, 1975) was included to determine whether perceptions of abusiveness might also be related to more egalitarian views.

Relationship Locus of Control Scale. To assess whether ratings were influenced by perceptions that one can exert control in relationships, the context subscale of the Marital Locus of Control Scale (Miller, Lefcourt, \& Ware, 1983) was utilized. Items were modified to refer to a dating partner rather than spouse. This 15 -item subscale measures the extent to which positive and negative relationship experiences are perceived as stemming from uncontrollable contextual characteristics.

Just World Scale. This 20-item scale measures the tendency to believe that the world is a fair place and that people have experiences in line with their behavior (Rubin \& Peplau, 1975). This scale was included to test whether persons believing people are treated as they deserve would rate vignettes as less abusive.

Philosophy of Human Nature Scale. Two 10-item subscales of this scale measure expectancies people have about the ways others generally behave (Wrightsman, 1964). The Complexity Subscale measures the extent to which persons are perceived as complex and difficult to understand, and the Variability Subscale measures beliefs about the extent of individual differences and changeability in 
basic human nature. Viewing humans as complex and changeable in nature was assessed to see whether this may impact rating the abusiveness of behaviors in varied contexts.

Intolerance of Ambiguity. This 16-item scale measures the tendency to perceive ambiguous situations as a threat. Ambiguous situations are novel, complex, or insoluble and may arouse responses to threat such as denial, anxiety, discomfort, avoidance, or destructive behavior (Budner, 1962). A higher level of intolerance of ambiguity was expected to be related to higher ratings of abusiveness.

Rigidity Scale. This 20-item scale measures opposition to change and intolerance of ambiguity (Meresko et al., 1954). This trait was expected to produce similar results as the Intolerance of Ambiguity Scale.

\section{Analyses}

A t-test was used to assess whether there existed effects for participant gender on mean abusiveness ratings across vignettes. Correlational analyses were used to assess associations between mean abusiveness ratings across vignettes and past experiences of initiation and receipt of psychological aggression, as well as between abusiveness ratings across vignettes and each of the eight measures of bias, attitudes, and traits. For these analyses, we used Bonferroni adjustments of significance level due to the number of comparisons within each set of correlations. Factorial analyses of variance were used to examine effects on abusiveness ratings for each of the 17 vignettes by context (less problematic versus more problematic), gender of initiator (female versus male), and the interaction between context and initiator's gender. Because our data structure (e.g., different participants completing different items) did not allow grouping of context items in multivariate analyses. This necessitated 17 separate factorial analyses, and we erred toward stringency via Bonferroni adjustments of significance level across all 17 tests (significance criterion $\mathrm{p}<.003$ ).

\section{Results}




\section{Effects of Participant Gender on Abusiveness Ratings}

A t-test indicated no differences between mean abusiveness rating across all 17 vignettes for males $(M=6.19)$ versus females $(M=6.13), \underline{t}(129)=0.25$, $\underline{\text { ns }}$. T-tests for participant gender effects on each of the 17 items indicate that differences in ratings by males and females did not approach significance for any individual item.

\section{Association of Abusiveness Ratings to Past Psychological Aggression}

Correlational analyses showed no association between mean abusiveness rating across all 17 vignettes and past initiation of psychological aggression, $\underline{r}=.03$, and no association between mean abusiveness rating across vignettes and past receipt of psychological aggression, $\underline{\mathrm{r}}=.10$, both $\underline{\mathrm{ns}}$.

\section{Association of Abusiveness Ratings to Response Bias, Attitudes, and Traits}

Correlational analyses showed no association between abusiveness ratings across vignettes and self-deception, $\underline{\mathrm{r}}=-.03$, impression management, $\underline{\mathrm{r}}=.02$, interpersonal sensitivity, $\underline{\mathrm{r}}=-.12$, paranoia, $\underline{\mathrm{r}}=-.01$, hostility, $\underline{\mathrm{r}}=-.11$, egalitarian sex roles, $\underline{\mathrm{r}}=-.01$, external relationship locus of control, $\underline{\mathrm{r}}=-.08$, just world, $\underline{\mathrm{r}}=-.21$, complexity of human nature, $\underline{\mathrm{r}}=-.23$, variability of human nature, $\underline{\mathrm{r}}=-.15$, intolerance of ambiguity, $\underline{\mathrm{r}}=-.10$, or rigidity, $\underline{\mathrm{r}}=-.01$, all $\underline{\mathrm{ns}}$. Thus, ratings of the psychologically aggressive behaviors were not significantly influenced by this range of measured personality traits and attitudes. ${ }^{4}$

\section{Analyses of Context and Gender Effects on Abusiveness Ratings}

Factorial analyses of variance with Bonferroni adjustments for number of tests were used to examine effects on abusiveness ratings for each of the 17 vignettes by context, gender of initiator, and the interaction between context and initiator's gender. For ease of discussion, we have grouped

\footnotetext{
4 Because correlations for just world and complexity of human nature were of marginal significance ( $p<.05$ versus the $\mathrm{p}<.004$ required by our Bonferroni-adjusted criterion), we conducted an exploratory regression to assess joint significance of these variables in accounting for variance in abusiveness ratings. Just world and complexity of human nature collectively accounted for a small but significant amount $(10 \%)$ of variance in ratings, $\mathrm{F}(1,128)=6.92, \mathrm{p}<.01$, and may warrant exploration in future research.
} 
these analyses according to the four types of contexts discussed previously: pattern or sequence of behavior, harm to the recipient evident, behavior as consistent with relationship dynamics, and behavior based in norms.

\section{$\underline{\text { Pattern or Sequence of Behavior }}$}

Five vignettes examined context effects of pattern or sequence of behavior. These included several vignettes portraying isolated or one-time psychologically aggressive behaviors versus an ongoing pattern of psychologically aggressive behavior (Vignettes A, B, \& C in Appendix I), one vignette portraying psychologically aggressive behavior stemming from an argument versus coming "out of the blue" (Vignette D), and one vignette portraying psychological aggression following strong provocation versus weak provocation (Vignette E). We hypothesized that the latter context for each vignette — the ones portraying patterns or unprovoked behavior-would be rated as more abusive than those portraying isolated incidents or behavior that followed from some provocation.

Only one of these vignettes (Vignette E) demonstrated significant effects. This vignette portrayed one partner threatening physical violence against the other, with one context condition representing strong provocation from the recipient (making out with the initiator's best friend at a party; E1), and the other representing weak provocation (pointing out some of the initiator's small flaws; E2). Ratings for this vignette showed effects for gender of the initiator, $\mathrm{F}(1,127)=87.60$, p $<.001$, but no effects for context or the interaction term. The psychologically aggressive action (physical threat) was viewed as vastly more abusive when perpetrated by a male $(\mathrm{M}=7.57)$ than by a female $(\mathrm{M}=4.84)$.

\section{Harm Evident to the Recipient}

Four vignettes examined context effects of harm evident to the recipient of a psychologically aggressive behavior. These included one vignette in which neither partner is bothered by the psychologically aggressive behavior versus one partner is bothered by it (Vignette F), one vignette in 
which no harm is evident from the behavior versus the recipient is interpersonally sensitive and feels wounded by it (Vignette G), one vignette in which the recipient reacts to the psychologically aggressive behavior with amusement versus becoming depressed (Vignette $\mathrm{H}$ ), and one vignette in which the recipient reacts to the psychologically aggressive behavior by devaluing the initiator versus being devastated by it (Vignette I). We hypothesized that the latter context for each vignette-the ones portraying evident harm to the recipient—would be rated as more abusive than those in which no harm was evident.

Two of these vignettes showed significant effects. The first (Vignette F) portrayed two partners arguing with one another, with one context condition representing that neither partner seems bothered (F1), and the other representing that one partner experiencing anxiety and stress from the conflict (F2). Ratings for this vignette showed effects for context, $F(1,127)=27.23$, $p<$ .001 , but no effects for gender of initiator or for the interaction term. The psychologically aggressive action (arguing) was viewed as more abusive when one partner is bothered by the behavior $(\mathrm{M}=$ 6.77), than when neither partner seems bothered $(M=5.09)$.

The other vignette (Vignette H) portrayed one partner refusing to visit the other's family, with one context condition representing the recipient as reacting with amusement (teasing the initiator for being scared to visit; H1), and the other condition representing the recipient as becoming depressed and upset (H2). Ratings for this vignette showed effects for context, F $(1,127)$ $=27.99, \underline{\mathrm{p}}<.001$. The psychologically aggressive action (refusing to visit) was viewed as more abusive when the recipient reacted with depression $(M=5.74)$ than with amusement $(M=3.89)$. $\underline{\text { Behavior as Consistent with Relationship Dynamics }}$

Four vignettes examined context effects of the psychologically aggressive behavior being somewhat consistent or inconsistent with certain relationship dynamics. These included two vignettes in which monitoring or controlling behavior was enacted within an exclusive relationship 
versus within a casual relationship (Vignettes J \& K), one vignette in which one partner told a major lie about himself/herself to the other within a casual versus exclusive relationship (Vignette L), and one vignette in which the psychologically aggressive action occurred in a relationship that was previously happy versus conflictual (Vignette M). We reasoned that the latter context for each vignette portrayed behaviors more discordant with apparent relationship dynamics and would thereby be rated as more abusive. For instance, monitoring and controlling-although not desirable behaviors — might be given some latitude of acceptance in exclusive relationships, whereas lying about oneself may be more tolerated from a casual partner. Similarly, psychological aggression might be viewed as part of expected conflict in an unhappy versus happy relationship.

One vignette (Vignette M) demonstrated significant effects. This vignette portrayed one partner insisting that the other not speak to potential romantic rivals, with one context condition representing this in a previously happy relationship (M1), and one condition representing this in a conflictual relationship (M2). Ratings for this vignette showed effects for gender of the initiator, F $(1,127)=12.16, \underline{\mathrm{p}}<.001$, but no effects for context or the interaction of these. The psychologically aggressive behavior (insisting that one's partner not speak to rivals) was viewed as more abusive when initiated by a male $(M=6.99)$ than by a female $(M=5.81)$.

\section{Behavior Based in Norms}

Four vignettes examined context effects of psychologically aggressive actions having some basis in social norms. These included one vignette in which a partner reminds the other of personal flaws in private versus in public (Vignette N), one vignette in which a partner's psychologically aggressive action is supported by peers versus discouraged by peers (Vignette O), one vignette in which the psychologically aggressive action is said to be common versus no normative information is provided (Vignette P), and one vignette in which the initiator provides a rationale for the psychologically aggressive behavior versus no rationale is provided (Vignette Q). We hypothesized 
that the psychologically aggressive behavior would be viewed as more abusive under the latter context condition for each vignette because social norms promote greater tolerance for the former conditions. None of these vignettes demonstrated significant effects.

\section{Discussion}

Because our main hypothesis was that context influences perceptions of psychologically aggressive behavior, it was informative to find that demographics and trait/attitude variables, that we hypothesized might impact ratings, were not influential. Specifically, the findings demonstrated no effects on abusiveness ratings due to characteristics of our research participants, including participants' gender, past experiences with initiating or receiving psychological aggression, socially desirable responding, personality traits, or attitudes. This is actually somewhat surprising given the range of measured variables. However, the lack of influential extraneous factors allows for a less muddled consideration of main experimental manipulations.

\section{Main Effect of Gender of the Initiator of Psychological Aggression}

Across the 17 pairs of vignettes, there were occasional main effects indicating that particular psychologically aggressive behaviors initiated by males toward female recipients were perceived as more abusive than the same behavior initiated by a female toward a male. The gender-of-initiator effect was exemplified in two vignettes that involved physically threatening or controlling behaviors (e.g., threatening to punch partner, telling partner not to speak to rivals), which is consistent with the idea that females are not expected to be as dangerous as males in making threats or exercising

control. This finding is also in line with the study by Follingstad et al. (2004a), who found that even psychologists rated many behaviors by a husband as more egregious than by a wife. It is important to note that this effect does not appear to be due to the gender of the rater, as analyses of general and item-level effects on abusiveness ratings did not reveal significant differences.

\section{Main Effect of Context for Psychologically Aggressive Behaviors}


Across most of the contexts we examined, differences between means for less problematic and more problematic contexts were in the expected direction but failed to reach significance. This was the case for the contexts involving a pattern of behavior. Directionality of findings with limited trends indicated that a pattern of psychologically aggressive behavior could be perceived as more abusive than when the same behavior was viewed as an isolated event, consistent with conceptualizations that posit a pattern of behavior must exist before considering the behavior abuse (Loring, 1994). Contextual factors, however, were not so strong as to significantly influence participant ratings. The pattern hypothesis neared significance for behaviors which might be perceived as milder in nature, such as interrupting and diminishing a partner's viewpoint, as well as for behaviors that are considered more problematic, such as name calling. Context ratings were also in the expected direction when an aggressive action followed in a sequence of behavior that would make the reaction appear understandable (e.g., provocation), but these differences did not near significance.

When the context was that the recipient of psychologically aggressive behavior experienced harm, some behaviors were rated as more abusive, consistent with stated hypotheses. Behaviors, such as arguing and refusing to visit the partner's family, were perceived as more abusive when the recipient was emotionally wounded or actually experienced psychological symptoms such as anxiety and stress due to the behavior. This finding suggests that specific behaviors may at times be labeled negatively more on the basis of the recipient's reaction than on the behavior itself, creating problems for designating when an action is considered abusive. Negative emotional effects from teasing about a potentially sensitive topic and flirting in front of the partner resulted in higher abusiveness ratings but neither reached significance, and only the former displayed a trend. However, both of these psychologically aggressive behaviors resulted in very high overall means by participants, possibly indicating that these behaviors were considered strong violations of relationship conduct 
independent of context. Context effects regarding recipient harm present a quandary, in that the same action is appraised as a function of the recipient's reaction. Should we consider the initiator abusive when the other partner is vulnerable or sensitive to conflict, but not consider the initiator abusive if a recipient is not bothered by the behavior? These findings mirror those of a previous study (Follingstad et al., 2004b) in which lay persons — more so than psychologists—-tended to deem behaviors to be a greater violation when they had the potential to produce emotional hurt.

Findings regarding context effects of relationship dynamics were not aligned with our hypotheses. In the two vignettes for which we believed controlling behaviors would be more excusable within an exclusive versus casual relationship, nonsignificant findings were in the opposite direction. We had based our prediction on prior studies suggesting that persons in more intense, committed relationships may view themselves as having more "rights" to influence the other partner (Laner \& Thompson, 1982). A trend toward the opposite effect could suggest that anyone who would exercise this type of control when the other partner has already made a commitment may be viewed as exhibiting serious problems, with the controlling behavior being viewed as excessive. Or, the trend could indicate that any attempts at controlling a dating partner's behavior when not much of a relationship or commitment has been formed may be perceived by the recipient as way beyond acceptable boundaries. Effects were in the expected direction for the vignette in which one partner told a major lie about himself/herself to the other partner, but differences did not approach significance. The vignette in which one partner tells the other not to speak to potential rivals showed nearly equivalent ratings across contexts.

Inconsistent results were found for ratings of psychologically aggressive behaviors among the vignette pairs which varied normative influences. Findings showed a trend in the expected direction for an aggressive action performed in public being viewed as more abusive than the same action performed in private. However, we found weaker and even mixed directionality of mean 
ratings among the remaining vignettes in which normative information validated the occurrence of the psychologically aggressive behavior (i.e., information from peers, from a study of relationship behavior, or from rationale of an external triggering event).

\section{Summary and Limitations}

Overall, this initial exploration demonstrates only limited and highly specific support for context playing a role in extent to which a psychologically aggressive behavior is viewed as abusive. There was also some support for certain aversive interpersonal behaviors being viewed as more problematic when exhibited by men toward women than vice versa. This study informs the literature challenging appropriateness of the current measurement of "psychological abuse" through checklists of briefly stated items. Although most types of context exhibited trends in the expected direction, these rarely reached statistical significance. Our data structure, however, did not allow for unitary analyses of all contexts (i.e., via multivariate analyses of variance), necessitating Bonferroni adjustments to significance criteria; such adjustments err toward conservatism and may have produced false negatives (i.e., null findings) for marginal contexts such as pattern of behavior. Because Follingstad (2008) found fairly large discrepancies between college students' report of the numbers of psychologically aggressive behaviors (from brief descriptions) versus the number of those behaviors the respondents considered to actually be psychologically abusive, whether checklists can reasonably attest to subjective "abusiveness" of events remains unclarified.

The contexts which appeared to show the greatest influence involved when the recipient's reaction was emotionally negative as opposed to not experiencing emotional harm. This finding may be important in defining abusiveness of specific actions, in that behaviors may be deemed abusive on the basis of a recipient's reaction rather than on the behavior itself. Findings demonstrating that infliction of harm results in higher abuse ratings, however, could be an artifact of our instructions to participants. That is, our instructions (Appendix II) explicitly stated that "abuse implies harm has 
been inflicted, or could happen, as a result of the behavior." This finding thereby warrants further exploration.

Limitations of this study include that participants were undergraduate students who volunteered to participate in exchange for course credit, although the rated vignettes were specifically geared toward dating behavior and presumably would be applicable to many college students. However, bias from selection effects may exist, and responses from a nationally representative sample of persons in longer cohabiting relationships may serve to provide more data as to whether context is an important consideration. The concept of "context" may also need to be expanded, such that long-term relationship variables including general satisfaction level, current commitment level, etc. might be explored further for potential associations with abusiveness ratings.

In addition, the research is exploratory in nature, rather than a definitive examination of all possible contexts and psychologically aggressive behaviors. Further research is needed to systematically probe these findings, particularly those which demonstrated greater stability across vignettes. Specifically, using the same psychologically aggressive behavior across the range of contexts may help to clarify whether some contexts that did not show effects in this study might nevertheless influence perceptions of abusiveness given different types or aversiveness levels of behaviors.

\section{References}

Aguilar, R.J., \& Nightingale, N.N. (1994). The impact of specific battering experiences on the selfesteem of abused women. Journal of Family Violence, 9(1), 35-45

Budner, S. (1962). Intolerance of ambiguity. Journal of Personality, 30, 29-50.

Devine, D.J., Clayton, L.D., Dunford, B.B., Seying, R., \& Pryce, J. (2001). Jury decision making: 45 years of empirical research on deliberating groups. Psychology, Public Policy and Law, 7, 622-727.

Evenson, R., Holland, R., Mehta, S., \& Yasin, F. (1980). Factor analysis of the Symptom Checklist- 
90. Psychological Reports, 46, 695-699.

Follingstad, D.R. (2007). Rethinking current approaches to psychological abuse: Conceptual and methodological issues. Aggression and Violent Behavior, 12(4), 439-458.

Follingstad, D.R. (2008). Patterns of psychological aggression in dating relationships. Unpublished data. Lexington, KY: University of Kentucky.

Follingstad, D., Coyne, S., \& Gambone, L. (2005). A representative measure of psychological aggression and its severity. Violence and Victims, 20, 25-38.

Follingstad, D. R., \& DeHart, D.D. (2000). Defining psychological abuse of husbands toward wives: Contexts, behaviors, and typologies. Journal of Interpersonal Violence, 15(9), 891-920.

Follingstad, D.R., DeHart, D.D., \& Green, E.P. (2004a). Psychologists' judgments of psychologically aggressive actions when perpetrated by a husband versus a wife. Violence and Victims, 19(4), 435-452.

Follingstad, D.R., Helff, C.M., Binford, R.V., Runge, M.M., \& White, J.D. (2004b). Lay persons’ versus psychologists' judgments of psychologically aggressive actions. Journal of Interpersonal Violence, 19, 916-942.

Hoffman, P. (1984). Psychological abuse of women by spouses and live-in lovers. Women and Therapy, 3(1), 37-47.

Kowalski, R.M. (2001). Aversive interpersonal behaviors: On being annoying, thoughtless, and mean. In R.M. Kowalski (Ed.), Behaving badly: Aversive behaviors in interpersonal relationships. Washington, DC: American Psychological Association.

Laner, M.R., \& Thompson, J. (1982). Abuse and aggression in courting couples. Deviant Behavior, 3, 229-244.

Loring, M. (1994). Emotional abuse. New York: Lexington Books.

Maiuro, R.D. (2001). Sticks and stones may break my bones, but names will also hurt me: 
Psychological abuse in domestically violent relationships. In K.D. O’Leary \& R.D. Maiuro (Eds.), Psychological abuse in violent domestic relations, (p. ix-xx). New York: Springer.

McGoldrick, M., Giordano, J., \& Pearce, J.K. (1996). Ethnicity and family therapy. (2nd ed.). New York: Guilford Press.

Meresko, R., Rubin, M., Shontz, F., \& Morrow, W. (1954). Rigidity of attitudes regarding personal habits and its ideological correlates. Journal of Abnormal and Social Psychology, 49, 89-93.

Miller, P., Lefcourt, H., \& Ware, E. (1983). The construction and development of the Miller Marital Locus of Control Scale. Canadian Journal of Behavioural Science, 15, 266-279.

Murphy, C. M., \& Hoover, S. A. (1999). Measuring emotional abuse in dating relationships as a multifactorial construct. Violence and Victims, 14(1), 39-53.

O'Leary, K. D. (2001). Psychological abuse: A variable deserving critical attention in domestic violence. In K.D. O’Leary \& R.D. Maiuro, (Eds.) Psychological abuse in violent relations. New York: Springer.

Paulhus, D. (1988). Assessing self-deception and impression management in self-reports: The Balanced Inventory of Desirable Responding. Vancouver, BC: Canada: University of British Columbia.

Rubin, Z., \& Peplau, L. (1975). Who believes in a just world? Journal of Social Issues, 31, 65-89.

Smith, E., Ferree, M., \& Miller, F. (1975). A short scale of attitudes toward feminism. Representative Research in Social Psychology, 6, 51-56.

Straight, E., Harper, F., \& Arias, I. (2003). The impact of partner psychological abuse on health behaviors and health status in college women. Journal of Interpersonal Violence, 18, 1035-1054.

Vivian, D., \& Langhinrichsen-Rohling, J. (1994). Are bi-directionally violent couples mutually victimized? A gender-sensitive comparison. Violence and Victims, 9(2), 107-124.

Wrightsman, L. (1964). Assumptions about philosophies of human nature. Psychological Reports, 14, 743-751. 
Appendix I: Mean Ratings and F Values for Vignettes under Two Context Conditions*

\begin{tabular}{|c|c|c|}
\hline LESS PROBLEMATIC CONTEXT & MORE PROBLEMATIC CONTEXT & F $(1,127)$ \\
\hline \multicolumn{3}{|c|}{ Pattern or Sequence of Behavior } \\
\hline
\end{tabular}




\begin{tabular}{|c|c|c|}
\hline $\begin{array}{l}\text { friends unless he was there) towards Belinda? } \\
\text { (ISOLATED OCCURRENCE; M = 6.98) }\end{array}$ & (ONGOING OCCURRENCE; $\mathrm{M}=7.16$ ) & \\
\hline $\begin{array}{l}\text { C1. Kendall and Beth are in their early } 20 \text { s and have been } \\
\text { in a relationship for about a year. They have spent quite a } \\
\text { bit of time together over the year, and both seem invested } \\
\text { in the relationship. While they tend to have the usual } \\
\text { conflicts couples have, a few days ago in an argument, for } \\
\text { the first time ever, Kendall called Beth a "bitch" and a } \\
\text { "whore." } \\
\text { How psychologically abusive was Kendall's action (of } \\
\text { name-calling) towards Beth? } \\
\text { (FIRST OCCURRENCE; M = 5.69) }\end{array}$ & $\begin{array}{l}\text { C2. Katrina and Brian are in their early } 20 \text { s and have been } \\
\text { in a relationship for about a year. They have spent quite a } \\
\text { bit of time together over the year and both seem invested } \\
\text { in the relationship. While they tend to have the usual } \\
\text { conflicts couples have, lately Brian has been calling } \\
\text { Katrina a "bitch" and a "whore" almost every time they } \\
\text { argue. A few days ago in an argument, he did it again. } \\
\text { How psychologically abusive was Brian's action (of name- } \\
\text { calling) towards Katrina? } \\
\text { (ONGOING OCCURRENCE; M = 6.55) }\end{array}$ & $\mathrm{F}=7.39, \mathrm{p}=.007$ \\
\hline $\begin{array}{l}\text { D1. Andrea and Dan are in their early } 20 \text { s and have been } \\
\text { in a relationship for about a year. Most everyone } \\
\text { considers them to be a happy couple. The past week, } \\
\text { however, the two of them were having a serious } \\
\text { argument about how they were going to spend the } \\
\text { holidays. Both of them were getting pretty heated about } \\
\text { this topic when Dan told Andrea she was actually crazy } \\
\text { and should see a psychologist to get her head on straight. } \\
\text { How psychologically abusive was Dan's action (of telling } \\
\text { Andrea she is crazy and should see a psychologist) } \\
\text { towards Andrea? } \\
\text { (STEMS FROM AN ARGUMENT; M = 4.72) }\end{array}$ & $\begin{array}{l}\text { D2. Allen and Diane are in their early } 20 \text { s and have been } \\
\text { in a relationship for about a year. Most everyone } \\
\text { considers them to be a happy couple. One day when they } \\
\text { were taking a walk, out of the blue. Allen told Diane he } \\
\text { thought she was actually crazy and should see a } \\
\text { psychologist to get her head on straight. } \\
\text { How psychologically abusive was Allen's action (of telling } \\
\text { her she is crazy and should see a psychologist) towards } \\
\text { Diane? }\end{array}$ & $\mathrm{F}=2.24, \mathrm{p}=.137$ \\
\hline $\begin{array}{l}\text { E1. Marcus and Sherry are in their early } 20 \text { s and have } \\
\text { been in a relationship for about a year. They have been } \\
\text { reasonably happy together. Last week, during a heated } \\
\text { argument, Sherry told Marcus that she had been making } \\
\text { out with his best friend at a party last week. He became }\end{array}$ & $\begin{array}{l}\text { E2. Scott and Marcia are in their early 20s and have been } \\
\text { in a relationship for about a year. They have been } \\
\text { reasonably happy together. Last week, during a heated } \\
\text { argument, Marcia pointed out some small personal flaws } \\
\text { of Scott's. He became very angry and said that if she ever }\end{array}$ & $\mathrm{F}=2.24, \mathrm{p}=.137$ \\
\hline
\end{tabular}




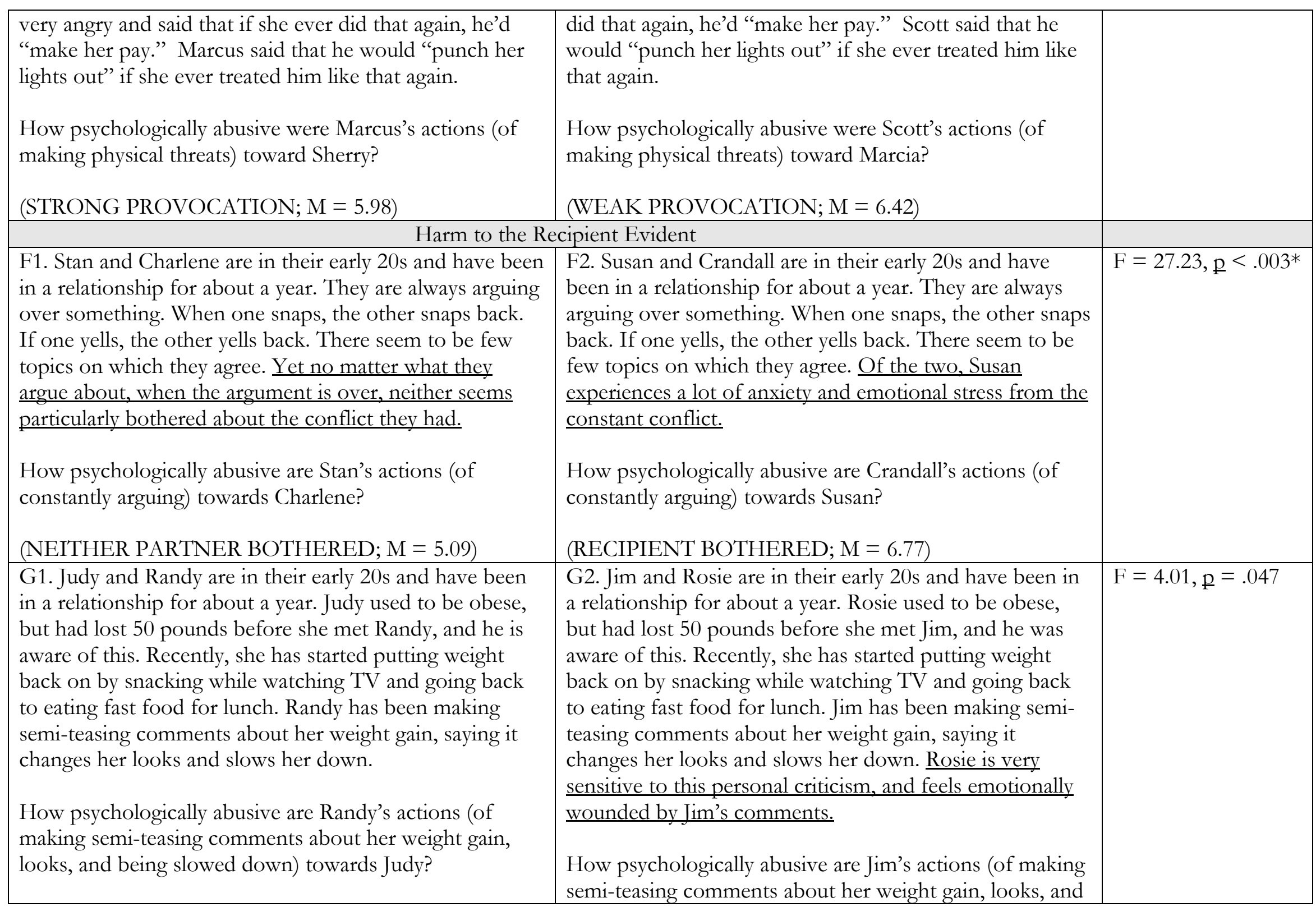




\begin{tabular}{|c|c|c|}
\hline (HARM NOT EXPLICIT; $\mathrm{M}=6.70$ ) & $\begin{array}{l}\text { being slowed down) towards Rosie? } \\
\text { (RECIPIENT WOUNDED; } \mathrm{M}=7.40 \text { ) }\end{array}$ & \\
\hline $\begin{array}{l}\text { H1. Ellen and Terrence are in their early } 20 \text { s and have } \\
\text { been in a relationship for about a year. The relationship } \\
\text { has become fairly serious over the year. Terrence knew } \\
\text { that it was extremely important to Ellen for him to meet } \\
\text { her family who lived several hundred miles away. Her } \\
\text { family is emotionally very close and very involved with } \\
\text { each other. Ellen has been asking Terrence for some time } \\
\text { for the two of them to visit her family. Even though it } \\
\text { would not have been a problem in any way for him to go, } \\
\text { and he was not anxious about it, Terrence refused to go. } \\
\text { Ellen has reacted to his seemingly unreasonable refusal by } \\
\text { teasing him. She told him that he must be a little scared to } \\
\text { meet her large and curious family. } \\
\text { How psychologically abusive was Terrence's action (of } \\
\text { refusing to visit her family) towards Ellen? } \\
\text { (RECIPIENT AMUSED; M = 3.89) }\end{array}$ & $\begin{array}{l}\text { H2. Eric and Tamara are in their early } 20 \text { s and have been } \\
\text { in a relationship for about a year. The relationship has } \\
\text { become fairly serious over the year. Eric knew that it was } \\
\text { extremely important to Tamara for him to meet her } \\
\text { family who lived several hundred miles away. Her family } \\
\text { is emotionally very close and very involved with each } \\
\text { other. Tamara has been asking Eric for some time for the } \\
\text { two of them to visit her family. Even though it would not } \\
\text { have been a problem in any way for him to go, and he } \\
\text { was not anxious about it, Eric refused to go. Tamara has } \\
\text { reacted to his seemingly unreasonable refusal by feeling } \\
\text { very hurt, and feeling that she must not be of much value } \\
\text { to him since he will not go with her. Because of this, she } \\
\text { has recently been somewhat depressed and upset. } \\
\text { How psychologically abusive was Eric's action (of } \\
\text { refusing to visit her family) towards Tamara? } \\
\text { (RECIPIENT DEPRESSED; M = 5.74) }\end{array}$ & $\mathrm{F}=27.99, \mathrm{p}<.003^{*}$ \\
\hline $\begin{array}{l}\text { I1. Agnes and Cameron are in their early 20s and have } \\
\text { been in a relationship for about a year. They were at the } \\
\text { mall today and ran into a really beautiful ex-girlfriend of } \\
\text { Cameron's. He gave her furtive glances and made a few } \\
\text { suggestive remarks as she gave him a big good-bye hug. } \\
\text { He never introduced Agnes. Agnes decided that he was a } \\
\text { erk and their relationship was not worth working on. } \\
\text { How psychologically abusive are Cameron's actions (of } \\
\text { flirting with the ex-girlfriend and not introducing Agnes) } \\
\text { towards Agnes? }\end{array}$ & $\begin{array}{l}\text { I2. Anthony and Cheryl are in their early } 20 \text { s and have } \\
\text { been in a relationship for about a year. They were at the } \\
\text { mall today and ran into a beautiful ex-girlfriend of } \\
\text { Anthony's. He gave her furtive glances and made a few } \\
\text { suggestive remarks as he gave her a big good-bye hug. He } \\
\text { never introduced Cheryl. Cheryl was devastated, more } \\
\text { sure than ever that she lacked something other women } \\
\text { had, so much that Anthony was too ashamed to even } \\
\text { introduce her. } \\
\text { How psychologically abusive are Anthony's actions (of } \\
\text { flirting with the ex-girlfriend and not introducing Cheryl) }\end{array}$ & $\mathrm{F}=1.81, \mathrm{p}=.181$ \\
\hline
\end{tabular}




\begin{tabular}{|c|c|c|}
\hline (RECIPIENT DEVALUES INITIATOR; M = 6.86) & $\begin{array}{l}\text { towards Cheryl? } \\
\text { (RECIPIENT DEVASTATED; } \mathrm{M}=7.33 \text { ) }\end{array}$ & \\
\hline \multicolumn{3}{|c|}{ Behavior Consistent with Relationship Dynamics } \\
\hline $\begin{array}{l}\text { K1. Larry and Michelle are in their early } 20 \text { s and have } \\
\text { been in a relationship for about a year. After dating for } 2 \\
\text { months, they decided to date each other exclusively and } \\
\text { they see each other almost every day. Over time, Larry } \\
\text { has begun to make a lot of personal decisions for } \\
\text { Michelle, such as choosing which of her friends she can } \\
\text { see, which activities she can do without him, how much } \\
\text { she can drink, whether she should smoke, and how she } \\
\text { should spend her free time. } \\
\text { How psychologically abusive were Larry's actions (of } \\
\text { making personal decisions for her) towards Michelle? }\end{array}$ & $\begin{array}{l}\text { K2. Lola and Mel are in their early 20s and have been } \\
\text { dating each other casually over the last year. They might } \\
\text { go out 1-2 times a month and they both date other people } \\
\text { as well. They have not indicated any interest in making a } \\
\text { commitment to each other, but rather have seemed } \\
\text { willing to keep the relationship a casual one. Over time, } \\
\text { Mel has begun to make a lot of personal decisions for } \\
\text { Lola, such as choosing which of her friends she can see, } \\
\text { which activities she can do without him, how much she } \\
\text { can drink, whether she should smoke, and how she } \\
\text { should spend her free time. } \\
\text { How psychologically abusive were Mel's actions (of }\end{array}$ & $\mathrm{F}=6.58, \mathrm{t}$ \\
\hline
\end{tabular}




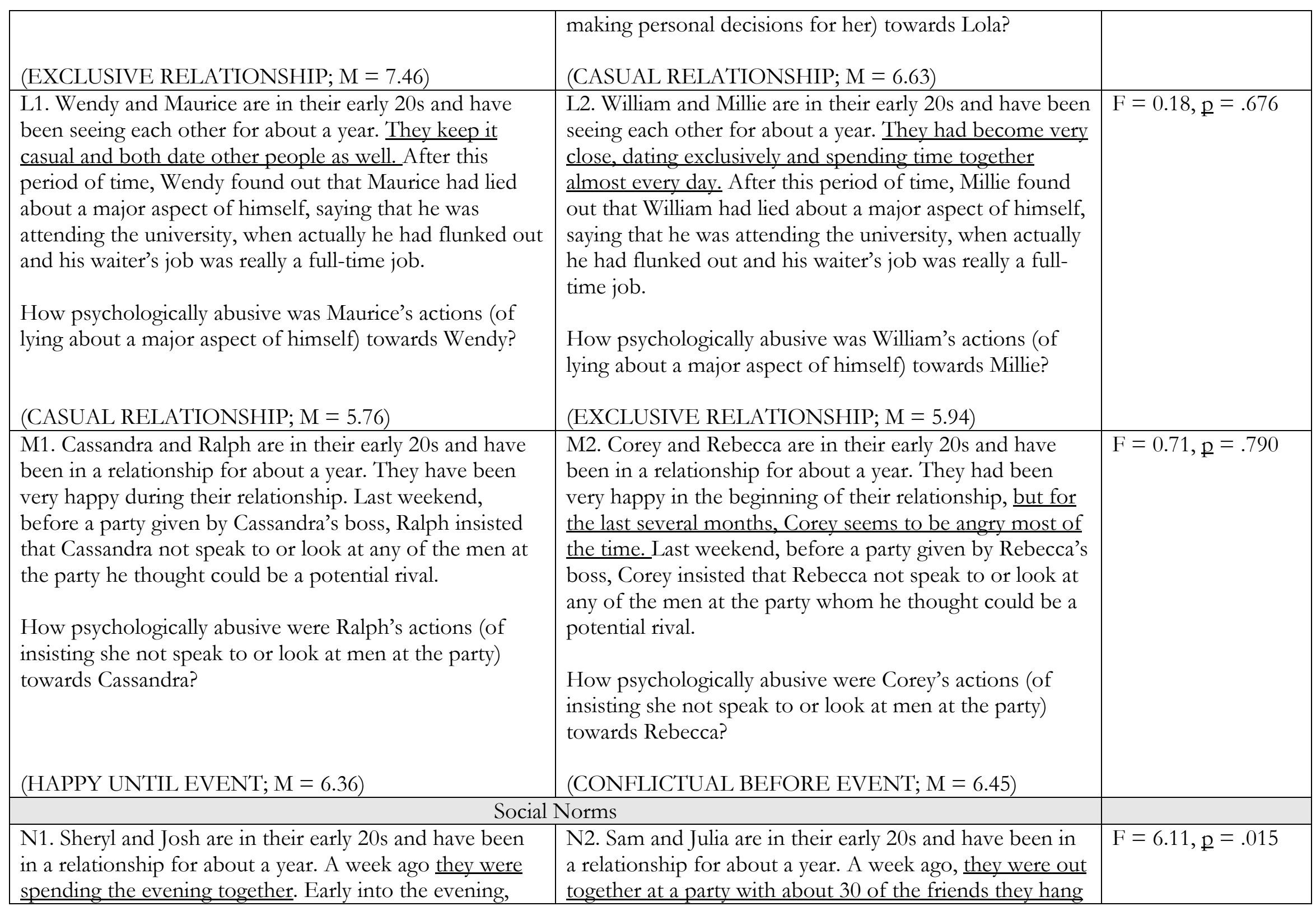




\begin{tabular}{|c|c|c|}
\hline $\begin{array}{l}\text { Josh became angry at Sheryl and began reminding her } \\
\text { about some of her personal flaws about which she is } \\
\text { embarrassed. } \\
\text { How psychologically abusive was Josh's action (of } \\
\text { reminding her about her personal flaws) towards Sheryl? }\end{array}$ & $\begin{array}{l}\text { out with and who know them best. Early into the } \\
\text { evening, Sam became angry at Julia and he began telling } \\
\text { people at the party about some of her personal flaws } \\
\text { about which she is embarrassed. } \\
\text { How psychologically abusive was Sam's action (of telling } \\
\text { people of her flaws) towards Julia? } \\
\text { (HAPPENED IN PUBLIC; M = 6.16) }\end{array}$ & \\
\hline $\begin{array}{l}\text { How psychologically abusive was Tommy's action (of } \\
\text { saying these things) towards Joyce? } \\
\text { (PEERS SUPPORT ACTION; M = 3.47) }\end{array}$ & $\begin{array}{l}\text { How psychologically abusive was Jackson's action (of } \\
\text { saying these things) towards Taya? } \\
\text { (PEERS DISCOURAGE ACTION; M = 3.88) }\end{array}$ & \\
\hline $\begin{array}{l}\text { P1. Colin and Tina are in their early } 20 \text { s and have been a } \\
\text { relationship for about a year. They have had the usual } \\
\text { good times and conflicts of dating couples. Tina feels that } \\
\text { the relationship is quite good except that it bothers her } \\
\text { that Colin always insists that the problems in the } \\
\text { relationship are her entire fault. Studies show that this } \\
\text { type of blaming behavior is quite common in dating } \\
\text { relationships. }\end{array}$ & $\begin{array}{l}\text { P2. Carrie and Tim are in their early 20s and have been a } \\
\text { relationship for about a year. They have had the usual } \\
\text { good times and conflicts of dating couples. Carrie feels } \\
\text { that the relationship is quite good except that it bothers } \\
\text { her that Tim always insists the problems in the } \\
\text { relationship are her entire fault. } \\
\text { How psychologically abusive are Tim's actions (of }\end{array}$ & $\mathrm{F}=0.22$, \\
\hline
\end{tabular}




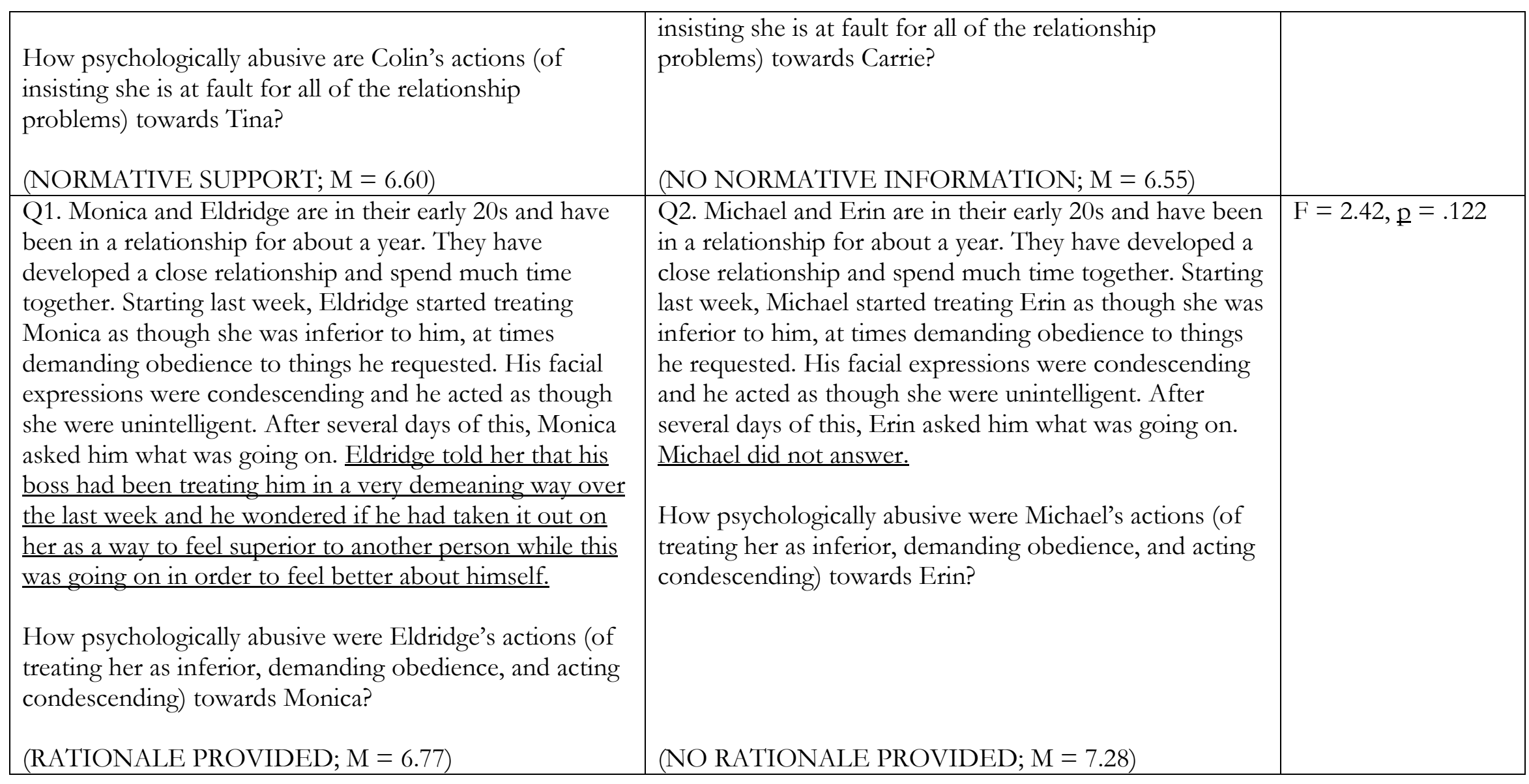

*Underlining is used here to emphasize differences between the two conditions and did not appear in original vignettes. This appendix shows only male-to-female psychological aggression vignettes. Female-to-male psychological aggression vignettes were essentially the same with names reversed and only minor modifications to wording based on gender of initiator and recipient (e.g., the derogatory names used in Vignette C were changed to "bastard" and a "pussy" when directed at a male). 


\section{Appendix II: Instructions to Participants}

The following survey contains descriptions of behaviors that can occur between couples while in a dating relationship. Please read the scenarios, and then rate the behaviors according to the scale given. The scale ranges from 1 - 10, where a choice of " 1 " indicates the behavior is "not psychologically abusive at all," and a choice of " 10 " indicates the behavior is "extremely psychologically abusive." Please try to use the full range of options, if they match your opinions. In other words, remember to consider the ends of the scale, as well as all of the points in between, when making your rating choice.

To assist with rating, the following definitions are provided. PLEASE READ THIS CAREFULLY and keep them in mind when you are asked to rate the behaviors on a continuum of psychological "abuse:"

There are many ways that couples can interact that can be considered aggressive in terms of the intention of the actions. These could be physical or psychological. "Psychological aggression" is a term used to designate the full range of psychological actions that can be used to aggress against a partner in an intimate relationship. In other words, these could include very mild actions all the way through the most severe things that a couple might do. As a way to distinguish "psychological abuse" from "psychological aggression," we want you to think of the term "psychological abuse" as describing the subset of psychologically aggressive behaviors that are more egregious and severe which are expected to produce psychological harm.

Therefore, "psychological abuse" is considered a more severe and extreme form of psychological aggression. The term "abuse" implies some threshold has been crossed which suggests the level of severity of that behavior is above and beyond what is considered "bad relationship behavior." Abuse implies harm has been inflicted, or could happen, as a result of the behavior(s). Please keep in mind that there is no time limit on answering and there are no right or wrong answers. Please rate each scenario as to how you view it and to the best of your ability. 